University of Nebraska - Lincoln

DigitalCommons@University of Nebraska - Lincoln

Educational Psychology Papers and

Publications

Educational Psychology, Department of

$10-2010$

\title{
A longitudinal study of student-teacher relationship quality, difficult temperament, and risky behavior from childhood to early adolescence
}

\author{
Kathleen Moritz Rudasill \\ University of Nebraska-Lincoln, kmrudasill@vcu.edu \\ Thomas G. Reio Jr. \\ Florida International University, reiot@fiu.edu \\ Natalie Stipanovic \\ University of Louisville, natalie.kosine@louisville.edu \\ Jennifer E. Taylor \\ Vanderbilt University, jennifer.e.taylor@Vanderbilt.Edu
}

Follow this and additional works at: https://digitalcommons.unl.edu/edpsychpapers

Part of the Educational Psychology Commons

Rudasill, Kathleen Moritz; Reio, Thomas G. Jr.; Stipanovic, Natalie; and Taylor, Jennifer E., "A longitudinal study of student-teacher relationship quality, difficult temperament, and risky behavior from childhood to early adolescence" (2010). Educational Psychology Papers and Publications. 120.

https://digitalcommons.unl.edu/edpsychpapers/120

This Article is brought to you for free and open access by the Educational Psychology, Department of at DigitalCommons@University of Nebraska - Lincoln. It has been accepted for inclusion in Educational Psychology Papers and Publications by an authorized administrator of DigitalCommons@University of Nebraska - Lincoln. 


\title{
A longitudinal study of student-teacher relationship quality, difficult temperament, and risky behavior from childhood to early adolescence
}

\author{
Kathleen Moritz Rudasill, ${ }^{1}$ Thomas G. Reio Jr., ${ }^{2}$ \\ Natalie Stipanovic, ${ }^{1}$ and Jennifer E. Taylor ${ }^{3}$ \\ 1. University of Louisville, Louisville, KY \\ 2. Florida International University, Miami, FL \\ 3. Vanderbilt University, Nashville, TN \\ Corresponding author - K. M. Rudasill
}

\begin{abstract}
This study examines the mediating role of student-teacher relationship quality (conflict and closeness) in grades 4,5 , and 6 on the relation between background characteristics, difficult temperament at age $4 \frac{1}{2}$ and risky behavior in 6 th grade. The longitudinal sample of participants $(N=1156)$ was from the NICHD Study of Early Child Care and Youth Development. Structural equation modeling was used to estimate paths from (a) background characteristics to student-teacher relationship quality and risky behavior, (b) temperament to student-teacher relationship quality and risky behavior, and (c) student-teacher relationship quality to risky behavior. Findings indicate that students' family income, gender, receipt of special services, and more difficult temperament were associated with risky behavior. In addition, student-teacher conflict was a mediator. Students with more difficult temperaments were more likely to report risky behavior and to have conflict in their relationships with teachers. More conflict predicted more risky behavior. Closer student-teacher relationships were associated with less risky behavior. Results suggest negative relationships, specifically student-teacher relationships, may increase the risk that certain adolescents will engage in risky behavior.
\end{abstract}

Keywords: maladaptive risk-taking, temperament, student-teacher relationships, adolescence, structural equation modeling 
$A$ dolescence is an important developmental period characterized by exploration and experimentation where youth test their strengths and limitations and the boundaries of societal norms (Gardner and Steinberg, 2005; Reio, 2010; Steinberg, 2003, 2008). Risky behavior (either adaptive or maladaptive) during adolescence is widespread, cutting across race, gender, and socioeconomic status. Risky behavior is adaptive when the benefits of an activity may outweigh the potential hazards (e.g., entering an election for a school office). Risky behavior is maladaptive when the activity's hazards outweigh any benefits (e.g., smoking cigarettes in the school bathroom). Current research on risky behavior focuses primarily on maladaptive risk and its related behaviors (e.g., smoking, drinking, unprotected sex, and drug experimentation) because of the short- and longterm health and development consequences associated with these behaviors (Byrnes, Miller, \& Schafer, 1999). Adolescents who initiate maladaptive risky behavior (e.g., sexual intercourse, physical violence, and alcohol consumption) in early adolescence (i.e., ages 11-14; Thompson et al., 2010) as compared to adolescents involved in such behavior in later adolescence, are at greater risk of developing poorer health in adulthood, lower educational attainment, and less economic success (Harris, Duncan, \& Boisjoly, 2002). Further, early initiation of risky behavior exposes adolescents to harmful effects for longer periods. Indeed, maladaptive risky behaviors may increase the likelihood of negative outcomes such as addiction, reckless driving, unintentional injury, and HIV infection. From a societal perspective, maladaptive risky behavior is costly (Reyna \& Farley, 2006). For example, the direct medical costs attributed to smoking exceed $\$ 50$ billion annually in the US (Dowdell, 2002).

Certain characteristics are associated with increases in an adolescent's likelihood of engaging in maladaptive risky behavior. Research demonstrates that some background characteristics (i.e., sex, socioeconomic status, and special education identification) and temperament (e.g., activity level and anger) are linked to adolescents' engagement in maladaptive risky behavior (Wills, Sandy, \& Yaeger, 2000). Moreover, recent research has identified factors that may explain why some adolescents are less likely to engage in maladaptive risky behaviors, such as positive relationships with teachers (Baker, 2006; DiLalla et al., 2004; Hamre and Pianta, 2001; Williams et al., 2000). These student-teacher relationships are also influenced by background characteristics (e.g., Hamre \& Pianta, 2001) and temperament (e.g., Rudasill and Rimm-Kaufman, 2009; Rydell et al., 2005). Consequently, there are two primary goals of this longitudinal study. The first is to understand associations between students' background and early temperament characteristics and the quality of their later relationships with teachers (in grades 4, 5, and 6) and maladaptive risky behavior in 6th grade. The second is to examine the mediating role of students' relationships with their teachers in 4th, 5th, and 6th grades on the associations between background characteristics and temperament and maladaptive risky behavior in early adolescence. 


\section{Theoretical grounding}

This study's theoretical framework stems from the bioecological model of development, which suggests that development is best understood when considered in the context of the environmental systems with which an individual has regular interactions (Bronfenbrenner, 1995, 1999; Bronfenbrenner and Morris, 1998). Thus, a comprehensive examination of students' behaviors must include consideration of characteristics of students and their environments (Pilgrim, Luo, Urberg, \& Fang, 1999). The bioecological model provides a framework for understanding how environmental systems contribute to an individual's development and hypothesizes four system levels: (a) the microsystem - the immediate settings encountered by the developing person (e.g., home, school, and community) (b) the mesosystem - the interconnections among immediate settings (e.g., home-school relationships and church-community relationships), (c) the exosystem - the social systems with which individuals do not directly interact, but nonetheless may influence the individual's development (e.g., parent's work environment), and (d) the macrosystem - the larger cultural context (including subcultures and social classes) in which development occurs (e.g., maladaptive risk-taking occurs less in cultures where active religious participation is valued; Zuckerman, 2007). This model posits that development occurs through consistent and enduring bi-directional interactions (i.e., proximal processes) between an individual and the environment. Therefore, risk behaviors and their consequences are ecological phenomena that are established and perpetuated over time as the result of a complex interplay between intra- and inter-individual variables (i.e., proximal processes; Swearer \& Espelage, 2004).

A temperamentally difficult adolescent may be more likely to engage in risky behavior in adolescence and beyond; it could be that this relationship is explained, in part, by a lack of strong, supportive elements in the microsystem (Baker, 2006; DiLalla et al., 2004). An individual's positive interactions with family, school, and teachers may reduce the likelihood of maladaptive behavior; on the other hand, an adolescent's desire for peer norm congruence, despite the awareness that certain behaviors are risky, may increase the likelihood of maladaptive behavior (e.g., Voisin, DiClemente, Salazar, Crosby, \& Yarber, 2006). The environment that institutes and sustains risky behavior must be understood before effective risk prevention and intervention programs can be developed and implemented.

\section{Contributors to risky behavior}

Recent research links adolescent risky behavior to ecological or socio-demographic factors, income and gender, personal characteristics such as disability (Edwards, Mumford, Shillingford, \& Serra-Roldan, 2007), and peer groups. Youth from low income families are more likely to have early and unprotected sexual intercourse, engage in delinquent acts, and drop out of school than youth from higher income families (Blum et al., 2001; Edwards et al., 2007; Harris et al., 2002). In terms of gender, males in all age groups tend to engage in most types of risky behavior more frequently than females (Zuckerman, 2007). For example, older adolescent males are more likely than their female peers to use alcohol and carry a weapon (Blum et al., 2001). Students who have been identified with disabili- 
ties are more likely to engage in risky behavior than students who have not been likewise identified. These students are also more likely to engage in risky behavior earlier than students without disabilities which puts them at greater risk for harmful long-term effects from such behavior (Feldstein and Miller, 2006; Kuperman et al., 2001).

\section{Temperament and risky behavior}

An adolescent's decision to engage in risky behavior is linked in part to his or her temperament. Temperament is typically defined as an individual's manner of responding to the environment (Thomas \& Chess, 1977) and is widely conceptualized as biologically based. Through interaction with developmental and environmental forces, temperament is a primary building block of personality (Kagan, 1998; Moore et al., 2005; Rothbart and Bates, 2006). As such, children's temperament characteristics have been found to be relatively stable through childhood (Kagan et al., 1988; Resnick et al., 1986; Rothbart and Posner, 2005) and predictive of personality in early adulthood (Caspi \& Silva, 1995).

Although temperament is a multi-dimensional construct, it is broadly conceptualized as comprising two systems: reactivity and regulation. Reactivity refers to the individual's natural reaction to stimuli in the environment. Temperamental characteristics indicative of reactivity include negative emotionality, fear, anxiety, sadness, approach, frustration/anger, irritability, and activity (Rothbart \& Bates, 2006). Regulation refers to the individual's regulatory response to that reaction, and includes characteristics such as task persistence, inhibitory control, constraint, attention, and control (Rothbart \& Bates, 2006). Thus, reactivity and regulation work together to inform an individual's behavioral responses to stimuli. For example, a highly reactive boy may become easily angry; if this boy controls his anger by using a calming strategy, he has demonstrated regulation. However, if this boy is unable to control his anger and lashes out, this incident indicates low regulation. Typically a constellation of temperament characteristics that includes high reactivity and low regulation is used to define difficult temperament in research (Pluess and Belsky, 2009; Reid et al., 2009; Thomas and Chess, 1977). Therefore, the temperament characteristics examined in this study are indicative of high reactivity (i.e., high activity level, anger/frustration, and approach), and low regulation (i.e., low inhibitory control).

Recent research supports the notion that during early adolescence, those with difficult temperament constellations are more likely to engage in risky behavior (Caspi et al., 1997; Moore et al., 2005; Mylant et al., 2002; Thompson et al., 2010; Wills et al., 2000). Adolescents with low impulse control and high negative emotionality have been found to be more likely to engage in risky behavior like substance abuse (Caspi et al., 1997; Moore et al., 2005). For example, Moore et al. (2005) found that individuals with an irritable temperament are more likely to be heavy abusers of alcohol and other drugs. In addition, high ratings for negative emotionality and low ratings for constraint among 18- year-olds predicts engagement in risky behavior at age 21 (Caspi et al., 1997). Bijttebier, Vertommen, and Florentie (2003) found children with difficult temperaments are more likely to engage in maladaptive risk-taking that resulted in injury. Wills et al. (2000) linked difficult temperament and lack of self-control to risky behavior and early onset of substance abuse among early adolescents (before 12 years of age). Through their extensive review 
of the literature, Feldstein and Miller (2006) connected maladaptive risk-taking to the difficult temperamental characteristics of anger, negative affect, impulsivity, neuroticism, aggression, sensation seeking, and poor self-control. Collectively, this research suggests that characteristics indicative of a difficult temperament contribute to an adolescent's increased likelihood of engaging in maladaptive risky behavior.

\section{Student-teacher relationships}

Burgeoning literature points to the importance of understanding the influence of proximal processes like the development of high quality student-teacher relationships on children's and adolescents' outcomes (Baker, 2006; DiLalla et al., 2004; Edwards et al., 2007; Hamre and Pianta, 2001; Roeser et al., 1996). High-quality (positive) student-teacher relationships are high in closeness (i.e., mutual respect, caring, and warmth between teachers and students); by contrast, low-quality (negative) student-teacher relationships are high in conflict (i.e., discord and frustration or anger between teachers and students; Birch and Ladd, 1997; Hughes et al., 2005; Pianta, 2001; Pianta et al., 1995). For children in the elementary grades, there is evidence that positive student-teacher relationships are connected to children's successful adjustment to school, academic achievement, and school liking (Baker, 2006; Birch and Ladd, 1997). In addition, such positive relationships are related to decreases in children's aggression (Meehan, Hughes, \& Cavell, 2003), and increases in teachers' perceptions of their students' academic abilities (Hughes et al., 2005). On the other hand, negative student-teacher relationships in elementary school are associated with children's low academic achievement, low school connectedness, and poor self-direction (Birch \& Ladd, 1997). Moreover, Hamre and Pianta (2001) found children's negative relationships with teachers in kindergarten are predictive of (a) poor academic achievement and work habits through the middle elementary grades and (b) behavior problems through middle school.

Although students typically report a decrease in their connectedness with teachers in middle school (Lynch \& Cicchetti, 1997), the quality of these relationships remains important for positive student outcomes. The literature indicates that student-teacher relationship quality for middle school students, high school students, and students earning a general equivalency diploma (GED) predicts student achievement. That is, students with positive relationships with teachers tend to have higher school performance than their peers with negative student-teacher relationships (DiLalla et al., 2004; Gregory and Weinstein, 2004; Reio et al., 2009; Roeser et al., 1996). More germane to this study, evidence suggests that adolescents' positive relationships with teachers are connected to a host of healthy outcomes, such as prosocial behavior (Wentzel, 1998, 2002), responsibility (Wentzel, 1998, 2002), engagement in school (Wentzel, 2002; Zimmer-Gembeck et al., 2006), belongingness to school (Roeser et al., 1996; Wentzel, 2002), and psychological well-being (Herrero, Estevez, \& Musitu, 2006). In addition, Wentzel (2002) found teacher behaviors indicative of negative student-teacher relationships (i.e., negative feedback) are related to students' irresponsible behavior. Together, this evidence suggests that students who feel connected to school through positive relationships with teachers are more likely to behave prosocially and responsibly and, therefore, are less likely to engage in maladaptive, risky behavior. 
Research examining direct links between student-teacher relationships and adolescent risky behavior is limited. However, some studies have shown that students' perceptions of connectedness with teachers are associated with their risky behavior (Olsson et al., 2008; Voisin et al., 2006). For example, in a sample of high-risk adolescents (i.e., those in detention centers), Voisin et al. (2006) found low levels of connectedness with teachers are associated with reports of more risky behavior in the months before detainment. These studies suggest low student-teacher connectedness increases the likelihood of maladaptive risky behavior (Reio et al., 2009). Conversely, high student-teacher connectedness may reduce adolescents' likelihood of engaging in maladaptive risky behavior (Voisin et al., 2006).

\section{Background characteristics, temperament, and student-teacher relationships}

Research has identified some student characteristics (e.g. income and gender) as key predictors of student-teacher relationship quality (Evans, 1996; Saft and Pianta, 2001; Stuhlman and Pianta, 2002). Wyrick and Rudasill (2009) found third grade children from lower income families to have more conflict and less closeness in their relationships with teachers, and these results are congruent with other work (e.g., O'Connor \& McCartney, 2006). In addition, there is abundant support for the notion that boys tend to be rated as having more conflict and less closeness with their teachers than girls (Baker, 2006; Hamre and Pianta, 2001; Stuhlman \& Pianta, 2002; Hughes et al., 2005). There are also reports that students with disabilities are less likely to feel bonded to their teachers or school and are more likely to be unsatisfied with their teachers (Murray and Greenberg, 2001, 2006).

Few studies, however, have examined the contributions of temperament to the quality of the student-teacher relationship. Those that do exist have examined links between young children's quality of relationships with teachers and (a) shyness and effortful control (Rudasill and Rimm-Kaufman, 2009; Rudasill et al., 2006; Rydell et al., 2005), and (b) shyness and anger (Justice, Cottone, Mashburn, \& Rimm-Kaufman, 2008). These studies highlight the importance of considering both reactive (i.e., shyness and anger) and regulatory (effortful control) elements of temperament when understanding student-teacher relationships. Specifically, less shyness (Justice et al., 2008; Rudasill et al., 2006; Rydell et al., 2005), less anger (Justice et al., 2008), and more effortful control (Rudasill \& RimmKaufman, 2009) are associated with positive student-teacher relationships. Our searches of the literature have not uncovered any work investigating associations between other dimensions of difficult temperament (such as activity or approach) and the quality of students' relationships with teachers. In addition, the studies mentioned above were conducted with children in preschool or early elementary grades. However, drawing from literature on parent-child relationships, we find abundant support for the notion that a difficult temperament strains relationships and predicts poor social competence in adolescence (see Eisenberg et al., 2008 for a review).

\section{Purpose of the study}

A lack of protective proximal factors has been identified as a potential mechanism explaining maladaptive risk-taking. Blum et al. (2001) found that students with disabilities, in comparison to their non-disabled peers, are predisposed to factors that may increase their health risk behaviors. For instance, they report significantly less family connectedness, 
lower parental expectations for completing school, less parental presence in their daily lives, and lower levels of religiosity and self-esteem. Furthermore, Beitchman, Wilson, Douglas, Young, and Adlaf (2001) found that individuals with a learning disability at 12 years of age have more than a three-fold risk of developing a substance use disorder by the age of 19 if they are living in a single-parent household and have severe behavior problems. Feldstein and Miller (2006) reviewed literature on risk-taking in adolescence and found that interventions designed to increase adolescents' connectedness to family members reduce risktaking behavior in individuals with conduct problems or substance abuse. Thus, research suggests proximal processes (or lack thereof) with other individuals are potential mechanisms for understanding the association between student characteristics and risky behavior. However, there is no work that examines the potential mediating role of relationships with teachers in the association between student characteristics and risky behavior.

The current study extends existing research by examining the mediating role of studentteacher relationship quality on the relation between background characteristics and difficult temperament (assessed at age 4 1/2 years) and risky behavior in early adolescence. In addition, this study was designed to understand the extent to which early adolescents' background characteristics and difficult temperament are associated with the quality of their relationships with teachers in 4th through 6th grade. Thus, guided by the bioecological model (Bronfenbrenner, 1999; Bronfenbrenner and Morris, 1998), our longitudinal study brings together (a) literature connecting background characteristics and temperament to adolescent risky behavior and (b) literature pointing to the contributions of student-teacher relationships to adolescent risky behavior to address this gap in the research. Specifically, the current study models a hypothesized mediating role of student-teacher relationship quality on the association between students' background and temperament characteristics and their risky behavior. The models here allow for the examination of mediation with estimates of path coefficients between the proposed independent variables (i.e., background characteristics and temperament) and the outcome variable (i.e., risky behavior) both directly and indirectly through student-teacher conflict or closeness. Given the importance of understanding risky behavior in early adolescence to prevent long-term problems, we examine these research questions with early adolescents (i.e., 6th-grade students).

The first question was, To what extent are difficult temperament and background characteristics related to student-teacher relationship quality and risky behavior among early adolescents? We hypothesized that individuals with higher ratings for difficult temperament, those from low income families, boys, and students receiving special services will be more likely to have lower quality student-teacher relationships (e.g., more conflict and less closeness) and more risky behavior. Conversely, we anticipated that individuals with low ratings for difficult temperament, those from higher income families, girls, and students receiving no special services will be more likely to have higher quality studentteacher relationships and less risky behavior. The second question was, To what extent does student-teacher relationship quality mediate the associations between difficult temperament and background characteristics and risky behavior among early adolescents? We hypothesized that student-teacher relationship quality would mediate the association between difficult temperament and risky behavior and the association between background characteristics and risky behavior. That is, associations between difficult temperament and background characteristics and risky behavior will be explained in part by the quality of the teacher-child relationship. Specifically, students with difficult tempera- 
ment, male students, students from lower income families, and students with disabilities will have more conflict and less closeness with teachers, and more conflict and less closeness will, in turn, predict more risky behavior.

\section{Method}

\section{Participants}

Participants for this study were part of the National Institute of Child Health and Human Development Study of Early Child Care and Youth Development (NICHD SECCYD; http://secc.rti.org). Participants in the NICHD SECCYD were obtained at birth; specifically, researchers recruited mothers having babies in 1991 in hospitals in the regions surrounding 10 U.S. cities: Little Rock, AK; Irvine, CA; Lawrence, KS; Boston, MA; Philadelphia, PA; Pittsburgh, PA; Charlottesville, VA; Morganton, NC; Seattle, WA; and Madison, WI. A total of 5416 mother-child dyads were deemed eligible for participation and agreed to a follow-up contact. Of those, 1364 mother-child dyads were randomly selected for participation in the study. Reflecting the longitudinal nature of this study, data included for the current study were collected during Phases II and III of the NICHD SECCYD, when participants were $4 \frac{1}{2} 2$ years old (Phase II) and in 4 th, 5 th, and 6 th grade (Phase III). From the original sample of 1364 families, 1226 remained in the study at the start of Phase II. Of those, there was a small number $(n=70)$ of participants who were missing data on temperament, student-teacher relationship quality, and risk behavior. We chose to eliminate those participants, resulting in a final sample of 1156 participants (593 boys and 563 girls). The racial/ ethnic makeup of the sample was 82\% White; $12 \%$ Black/African American; $1.6 \%$ Asian/ Pacific Islander; 0.4\% American Indian, Eskimo, or Aleut; and 6\% Other. Of those making up the final sample, the percent with missing temperament subscale scores ranged from 8\% (Anger and Inhibitory Control) to 14\% (Approach). The percent with missing studentteacher relationship quality subscale scores ranged from $20 \%$ (Conflict and Closeness in 5th grade) to $26 \%$ (Conflict and Closeness in 6th grade). The percent with missing risky behavior scores ranged from 13\% (early adolescents' self-report and report of friends' risky behavior) to $14 \%$ (mothers' reports of early adolescents' risky behavior). Over $93 \%$ of the data were not nested (i.e., typically only 1 study child was assigned to a classroom). For example, in 6th grade, there were 750 classrooms with 1 child, 52 classrooms with 2 children, 4 classrooms with 3 children, and 1 classroom with 6 children.

\section{Measures}

\section{Early adolescent background characteristics}

Information about gender (i.e., sex) was obtained from mothers when children were one month old. Socio-economic status was measured from the income-to-needs ratio for the early adolescent's family when the participants were in the 5th grade. Because the NICHD SECCYD did not gather this information during the 6th grade, the 5th-grade data were used. The income-to-needs ratio was calculated by dividing the family pre-tax income by the family poverty threshold (determined by number of individuals in the home, and number of dependent children in the home). To determine study participants' access to special services, 6th-grade teachers provided the number of hours per week the early adolescent re- 
ceived special services (i.e., speech/language, special education resource placement, special education full-time placement, social services from the school, tutoring, English as a second language, bilingual education, Chapter 1 /Title 1 or other federally-funded services, or similar state-funded services). No data on special services receipt were available for 373 students. However, many students $(n=663)$ received no special services; therefore, special services was dichotomized as yes/no for receiving special services.

\section{Difficult temperament}

Temperament was measured in the NICHD SECCYD via the Children's Behavior Questionnaire (CBQ; Rothbart, Ahadi, \& Hershey, 1994) when participants were approximately $4 \frac{1}{2}$ years old. Mothers completed this instrument in the lab where they reported, on a 7-point Likert-type scale, the extent to which their $4 \frac{1}{2} 2$ year-olds exhibited various behaviors within the last 6 months. The four subscales applicable to this study are Activity, Anger/Frustration, Approach, and Inhibitory Control. Each subscale has 10 items, with possible item scores ranging from 1 (extremely untrue) to 7 (extremely true). Items from the Activity subscale include "Seems to always be in a big hurry to get from one place to another" and "Is full of energy, even in the evening." Items from the Anger/Frustration subscale include "Gets quite frustrated when prevented from doing something s/he wants to do" and "Becomes easily frustrated when tired." Items from the Approach subscale include "Becomes very excited before an outing (e.g., picnic, party)" and "When s/ he wants to do something, s/he talks about little else." Items from the Inhibitory Control subscale include "Has difficulty waiting in line for something (reflected)" and "Can easily stop an Activity when s/he is told 'no'." Higher subscale scores indicated greater Activity, Anger/Frustration, Approach, and Inhibitory Control. To keep directional valence of temperament subscale scores consistent across all four dimensions, Inhibitory Control subscale scores were reflected for analysis so that higher scores indicated lower Inhibitory Control (Cohen, Cohen, West, \& Aiken, 2003). For the current sample, internal consistency values for each subscale were .71 (Activity), .78 (Anger/Frustration), .65 (Approach), and .74 (Inhibitory Control). Internal consistency for item scores on all four subscales together was acceptable $(a=.75)$.

\section{Student-teacher relationship quality}

Student-Teacher Conflict and Closeness were assessed by participants' 4th-, 5th-, and 6th-grade teachers using scores from the 15-item version of the Student-Teacher Relationship Scale: Short Form (STRS; Pianta, 2001). The Conflict subscale, made up of 8 items, is designed to measure the extent to which a teacher feels that he or she is at odds with or experiences discord with a student. These items include "Dealing with this child drains my energy" and "This child and I always seem to be struggling with each other." The Closeness subscale, made up of 7 items, assesses a teacher's feelings of comfort and respect in his or her relationship with a student. These items include "I share an affectionate, warm relationship with this child" and "It is easy to be in tune with what this child is feeling." Responses were recorded on a 5 -point Likert-type scale $(1=$ definitely does NOT apply, $5=$ definitely applies), so the possible score range was 8 to 40 for Conflict and 7 to 35 for Closeness. Higher scores indicated more Conflict and more Closeness. Cronbach's alphas with the current sample were as follows: Conflict in grade $4(a=.88)$, grade $5(a=.88)$, and grade $6(a=.89)$; Closeness in grade $4(a=.84)$, grade $5(a=.86)$, and grade $6(a=.86)$. The individual com- 
pleting the STRS was either the teacher who taught the majority of the early adolescent's classes (i.e., elementary grades) or the language arts teacher (i.e., middle grades; NICHD Early Child Care Research Network, 2001). In cases where the language arts teacher completed the STRS, the measures of Conflict and Closeness reflect perceptions of teachers who did not spend all day or most of the day with the students.

Scores for 4th-, 5th-, and 6th-grade teachers were used for two reasons. First, scores were moderately correlated across years (for Conflict, $r s=.48$ to .53 and for Closeness, $r s=.21$ to .34). Second, consistent with the bioecological model (Bronfenbrenner, 1999; Bronfenbrenner and Morris, 1998), student-teacher relationship quality may have a cumulative effect on students' outcomes, so inclusion of scores from 4th through 6th grade provides a more comprehensive view of the quality of youths' relationships with their teachers over time.

\section{Early adolescent risky behavior}

Risky Behavior in 6th grade was assessed by early adolescent report and mother report. The early adolescents completed a version of the Risky Behavior Protocol (Conger \& Elder, 1994) that included 38 items: 19 items assessing their perceptions of how often their friends engaged in certain Risky Behavior and 19 parallel items assessing their own Risky Behavior. Because adolescents tend to socialize with those who share similar risktaking propensities and tend to be more forthcoming regarding the risky behaviors of their friends than themselves (Steinberg, 2003, 2007, 2008), both methods of assessment seemed optimal (Babalola, 2004; Chassin et al., 2004; Gardner and Steinberg, 2005; Stacy et al., 1990). For friends' Risky Behavior, all items began with "How many of the kids you play with or hang out with have ever..." whereas, for self-reported Risky Behavior, all items began with "How many times did you ever..." Risky Behaviors included riding in a car without a seatbelt, smoking cigarettes, drinking beer or other alcohol, stealing, and getting into gang fights. Responses were scored as follows: never $=0$, one or two times $=1$, and more than 2 times $=2$. Due to the low number of respondents who indicated "more than 2 times" on the questionnaire, responses were recoded as 0 (never) or 1 (one or more times) before calculating total Risky Behavior scores. Responses to the first 19 items were summed for a total friends Risky Behavior score $(a=.82)$, and responses to the second 19 items were summed for a total early adolescent self-report Risky Behavior score $(a=.73)$. Possible scores ranged from 0 to 19.

When the youth were in the 6th grade, their mothers reported their perceptions of their children's Risky Behavior over the previous 6-month period using the Risky Behavior Questionnaire (Conger \& Elder, 1994), a 30-item instrument that is similar to the Risky Behavior Protocol completed by early adolescents. All items began with "How often do you think your child has done the following..." and, like the Risky Behavior Protocol, the Risky Behaviors are listed afterward. Responses were scored as follows: never $=0$, one or two times $=1$, more than two times $=2$, and don't know $=0$. Responses were summed for a total early adolescent mother report Risky Behavior score $(a=.71)$. Possible scores ranged from 0 to 60 .

\section{Models and analyses}

Data were analyzed with structural equation modeling (SEM) using AMOS 6.0 (Arbuckle, 2007) software. We estimated two models to address our research questions, one with Student-Teacher Conflict as the mediator, and the other with Student-Teacher 


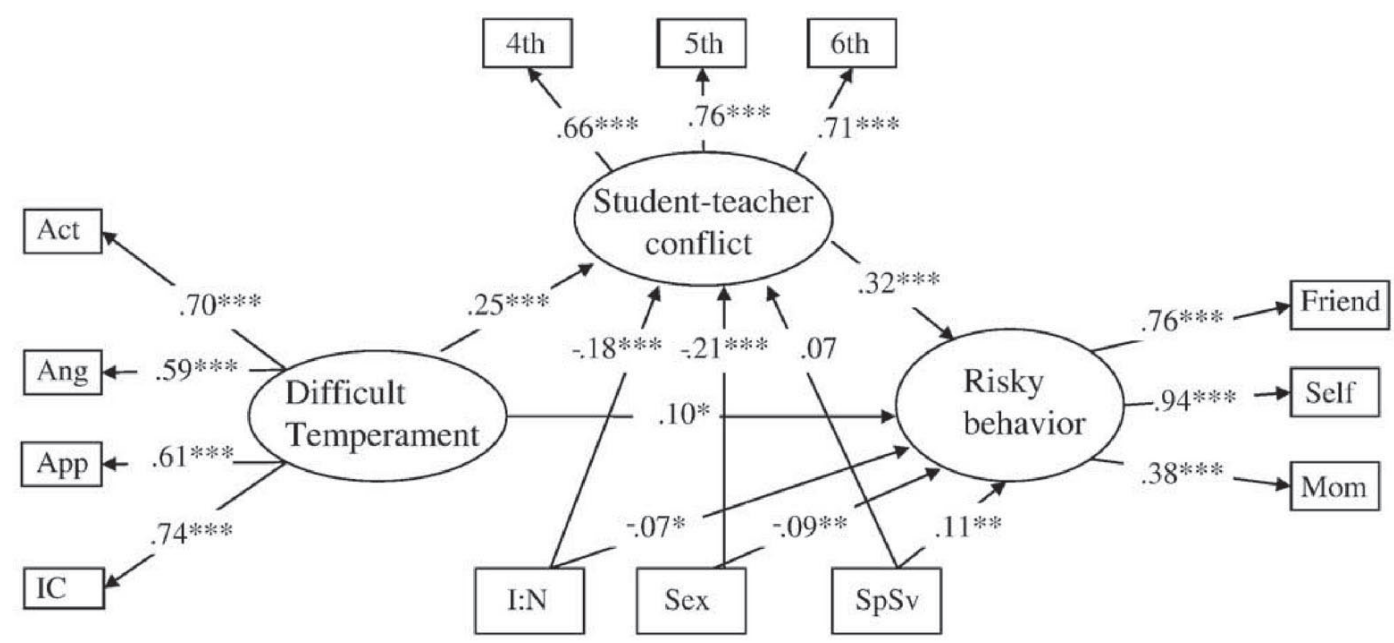

Figure 1. Risky behavior predicted by difficult temperament and student-teacher conflict. Note: I:N $=$ Income to needs ratio; Sex coded as $0=$ males, $1=$ females; $\mathrm{SpSv}=$ special services, coded as $0=$ no special services, $1=1$ or more hours/week of special services; Act = Activity; Ang = Anger $/$ Frustration; App = Approach; IC = Inhibitory Control (reverse coded); Friend $=$ Child's report of friends' risky behavior; Self $=$ Child's report of own risky behavior; Mom $=$ Mother's report of child's risky behavior. ${ }^{* * *} p<.001,{ }^{* *} p<.01,{ }^{*} p<.05$.

Closeness as the mediator. Two models were estimated for statistical and theoretical reasons. Correlations between Conflict and Closeness across grades 4 to 6 are somewhat weak (the strongest is -.36 between Conflict and Closeness in grade 4), supporting the notion guiding our analyses that Conflict and Closeness are different mechanisms in the classroom. For example, it is possible for children to have simultaneously highly conflictual and close relationships with teachers. On the other hand, some students have neither conflictual nor close relationships with teachers. Further still, some students are high on one and low on the other (e.g., Rudasill and Rimm-Kaufman, 2009; Rydell et al., 2005). Because Conflict and Closeness operate differently, it is important to understand how each works separately in mediating Risky Behavior.

The hypothesized longitudinal models described below are shown in Figures 1 and 2. The latent variable Difficult Temperament was indicated by the four CBQ subscale scores (i.e., Activity, Anger/Frustration, Approach, and Inhibitory Control). The latent variable Student-Teacher Conflict was indicated by the STRS Conflict scores from 4th, 5th, and 6th grades (Model 1), and the latent variable Student-Teacher Closeness was indicated by STRS Closeness scores from 4th, 5th, and 6th grades (Model 2). The latent variable Risky Behavior (in 6th grade) was indicated by three scores: estimates of friends Risky Behavior, self-reports of Risky Behavior, and mother's reports of Risky Behavior. Gender, income-to-needs ratio, and special services were observed variables.

Paths were specified from Difficult Temperament to Risky Behavior, and from Difficult Temperament to Student-Teacher Conflict (Model 1) or Student-Teacher Closeness (Model 2), and from Student-Teacher Conflict (Model 1) or Student-Teacher Closeness (Model 2) to Risky Behavior. Paths were also specified from early adolescent gender, fam- 


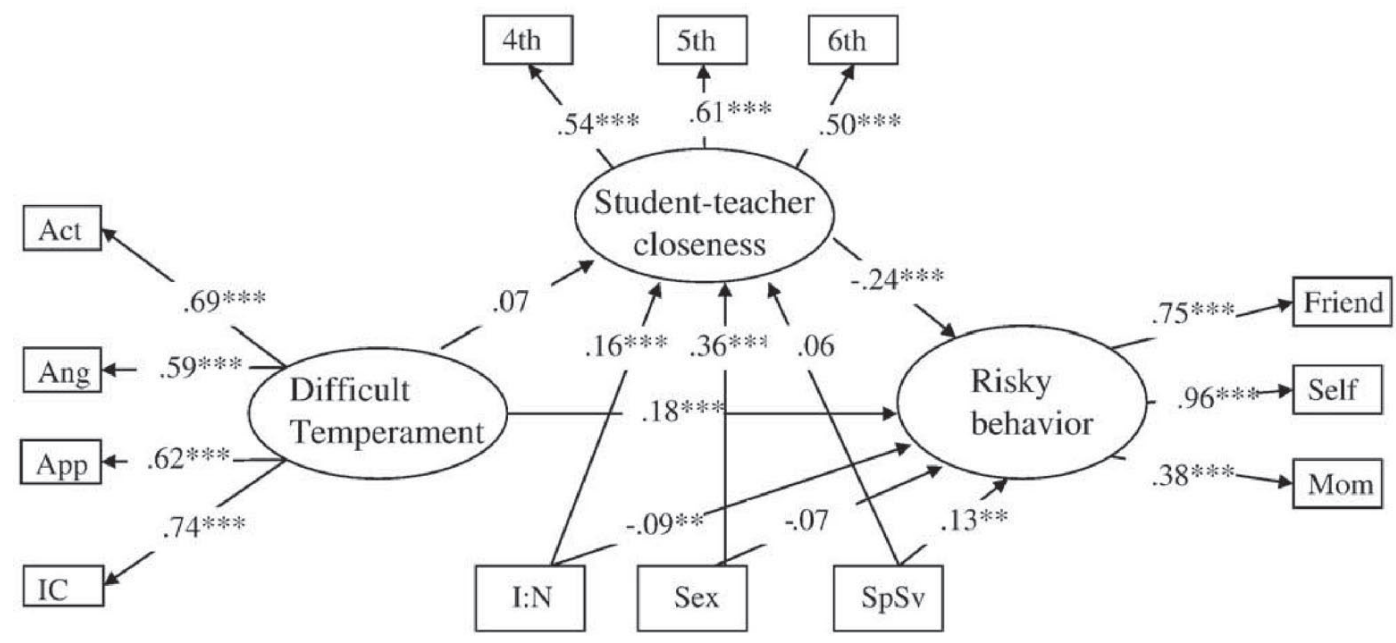

Figure 2. Risky behavior predicted by difficult temperament and student-teacher closeness. Note: I:N $=$ Income to needs ratio; Sex coded as $0=$ males, $1=$ females; SpSv $=$ special services, coded as $0=$ no special services, $1=1$ or more hours/week of special services; Act = Activity; Ang = Anger/Frustration; App = Approach; IC $=$ Inhibitory Control (reverse coded); Friend $=$ Child's report of friends' risky behavior; Self $=$ Child's report of own risky behavior; Mom $=$ Mother's report of child's risky behavior. ${ }^{* *} p<.001,{ }^{* *} p<.01,{ }^{*} p<.05$.

ily socioeconomic status (using the income-to-needs ratio), and special services to both Student-Teacher Conflict (Model 1) or Closeness (Model 2) and Risky Behavior. Because preliminary analyses suggested statistically significant correlations between Difficult Temperament and gender, Difficult Temperament and income-to-needs ratio, and income-to-needs ratio and special services, their correlations were freely estimated. The models were run using full information maximum likelihood estimation to accommodate missing data. To test for the mediating effect of the student-teacher relationship quality latent variables on the paths between Difficult Temperament and Risky Behavior and between background characteristics and Risky Behavior, confidence intervals for the distribution of the products of the indirect effects were calculated using PRODCLIN (MacKinnon, Fritz, Williams, \& Lockwood, 2007).

Model fit indices recommended by Hu and Bentler (1999) and Marsh et al. (2004) were used to evaluate the models. These fit indices were the chi-square statistic $\left(\chi^{2}\right)$, Incremental Fit Index (IFI), Tucker-Lewis Index (TLI), Comparative Fit Index (CFI), and Root Mean Square Error of Approximation (RMSEA). Good fit is indicated by a non-significant $\chi^{2}$, values close to 1 for IFI, TLI, and CFI, and values close to 0 for RMSEA (Byrne, 2001). Hu and Bentler posit that values close to .95 suggest good fit and encourage reference to multiple fit indices as well as the conceptual context for the model when evaluating goodness-of-fit. Similarly, Marsh et al. (2004) recommend using guidelines for determining acceptable fit with caution, taking into account other factors such as the theoretical foundation of the model and sample size. Because the structural components of the models include all possible paths, and thus had perfect fit, any misfit in the models can be attributed to the measurement components of the models. 


\section{Results}

Preliminary analyses were conducted to examine means, standard deviations, and ranges for all variables, and intercorrelations among variables (see Table 1). The average income-to-needs ratio $(M=4.53, S D=4.06)$ indicated that early adolescents from this sample tended to be from higher income households; an income-to-needs ratio of 3.0 is equivalent to "middle class" (Conger, Conger, \& Elder, 1997). The special services variable was dichotomized so that $0=$ no special services per week, and $1=1$ or more hours of special services per week $(M=0.14, S D=.35)$. Mean scores on the temperament subscales at age $4 \frac{1}{2} 2$ were: Activity $(M=4.78)$, Anger/Frustration $(M=4.74)$, Approach $(M=5.21)$, and reflected Inhibitory Control $(M=3.36)$. Early adolescents in this sample reported lower mean levels of Student-Teacher Conflict (4th grade: $M=11.14$; 5 th grade: $M=11.44$; 6th grade: $M=11.07$ ) than Student-Teacher Closeness (4th grade: $M=32.52$; 5 th grade: $M=31.85$; 6 th grade: $M=30.31$ ). These results are congruent with findings using a normative sample of younger children using the full STRS with 12 items for Student-Teacher Conflict and 11 items for Student-Teacher Closeness (Pianta, 2001). Early adolescents' estimates of Risky Behavior by their friends $(M=3.75, S D=2.93)$ were higher than estimates of their own Risky Behavior $(M=2.29, S D=1.98)$. Mean scores for mothers' reports of their adolescents' Risky Behavior were higher than the mean scores for adolescents' self-reports $(M=7.15, S D=4.70)$.

Correlation analyses (shown in Table 1) revealed many statistically significant correlations among the research variables. First, the dimensions of Difficult Temperament were moderately related, with correlations ranging in magnitude from .34 to .53 . Temperament dimensions at age $4 \frac{1}{2}$ years were also linked positively to Risky Behavior in 6th grade and Student-Teacher Conflict in 4th, 5th, and 6th grades. Second, early adolescents' Student-Teacher Conflict and Closeness scores in grades 4 through 6 were interrelated such that Conflict scores were positively correlated among all three grades, Closeness scores were positively correlated among all three grades, and Conflict scores were negatively related with Closeness scores in all three grades. Risky Behavior and Conflict scores were positively associated in all three grades, with the largest correlation between adolescents' self-report of Risky Behavior and Student-Teacher Conflict in grade $6(r=.30)$. Risky Behavior was negatively related to Student-Teacher Closeness, and the correlations ranged from - .09 to - .17. Risky Behavior was positively associated with the four Difficult Temperament variable scores as well, with correlations ranging from .06 to .27 .

\section{Model 1: Student-teacher conflict and risky behavior}

Figure 1 shows standardized parameter estimates for this model. Regression weights for all of the observed variables loading on latent variables were statistically significant, providing support for the latent variables in this model. The model provided good fit: $\chi^{2}{ }_{56}=260(p<.001), \mathrm{IFI}=.92, \mathrm{TLI}=.87, \mathrm{CFI}=.92$, and RMSEA $=.06$ (Byrne, 2001). Squared multiple correlations indicate that the model explained $18 \%$ of variance in Student-Teacher Conflict and $20 \%$ of variance in Risky Behavior. In terms of students' background characteristics, examination of path coefficients in this model pointed to significant paths from student gender $(-.21, p<.001)$ and family income-to-needs ratio $(-.18$, $p<.001)$ to Student-Teacher Conflict $\left(R^{2}=.18\right)$, and from student gender $(-.09, p=.007)$, 
Table 1. Means, standard deviations, ranges, and intercorrelations among variables.

\begin{tabular}{|c|c|c|c|c|c|c|c|c|}
\hline Variable & M & $S D$ & Range & 1 & 2 & 3 & 4 & 5 \\
\hline 1. Income:Needs & 4.53 & 4.06 & $0.11-28.7$ & - & & & & \\
\hline 2. Gender & & & & .05 & - & & & \\
\hline 3. Special Services & 0.14 & 0.35 & $0-1$ & $-.15^{\star *}$ & -.06 & - & & \\
\hline 4. Activity Level & 4.78 & 0.76 & $1.6-6.9$ & $-.14^{\star *}$ & $-.18^{* *}$ & .01 & - & \\
\hline 5. Anger/ Frustration & 4.74 & 0.83 & $1.6-6.9$ & -.06 & $-.09^{* *}$ & .06 & $.34^{* *}$ & - \\
\hline 6. Approach & 5.21 & 0.63 & $2.9-7.0$ & $-.08^{*}$ & -.04 & -.04 & $.46^{\star *}$ & $.44^{* *}$ \\
\hline 7. Inhibitory Control (reflected) & 3.36 & 0.76 & $1.6-5.7$ & $-.23^{\star *}$ & $-.23^{* *}$ & $.18^{* *}$ & $.53^{\star \star}$ & $.47^{* \star}$ \\
\hline 8. Conflict Grade 4 & 11.14 & 5.73 & 7-34 & $-.19^{* *}$ & $-.19^{* *}$ & $.17^{\star *}$ & $.19^{* *}$ & $.12^{* *}$ \\
\hline 9. Conflict Grade 5 & 11.44 & 5.74 & $7-35$ & $-.18^{* *}$ & $-.18^{* *}$ & .06 & $.18^{\star *}$ & $.14^{* *}$ \\
\hline 10. Conflict Grade 6 & 11.07 & 5.64 & $7-33$ & $-.16^{\star \star}$ & $-.23^{* *}$ & $.08^{*}$ & $.16^{\star *}$ & $.10^{* *}$ \\
\hline 11. Closeness Grade 4 & 32.52 & 5.11 & $12-40$ & $.16^{* *}$ & $.23^{* *}$ & -.07 & .01 & -.01 \\
\hline 12. Closeness Grade 5 & 31.85 & 5.37 & $14-40$ & $.07^{*}$ & $.17^{* *}$ & .05 & -.02 & .00 \\
\hline 13. Closeness Grade 6 & 30.31 & 5.74 & $12-40$ & .04 & $.20^{* *}$ & -.05 & -.02 & .03 \\
\hline 14. Risky Behavior (Self-report) & 2.29 & 1.98 & $0-16$ & $-.18^{* \star}$ & $-.19^{* *}$ & $.17^{\star *}$ & $.18^{* *}$ & $.12^{\star *}$ \\
\hline 15. Risky Behavior (Friends) & 3.75 & 2.93 & $0-18$ & $-.14^{*}$ & $-.14^{* *}$ & .08 & $.17^{\star *}$ & $.09^{* *}$ \\
\hline 16. Risky Behavior (Mother report) & 7.15 & 4.70 & $0-34$ & $-.20^{* *}$ & $-.17^{* *}$ & .05 & $.26^{\star *}$ & $.20^{\star \star}$ \\
\hline
\end{tabular}

${ }^{*} p<.05 ;{ }^{* *} p<.01$

family income-to-needs ratio $(-.07, p=.038)$, and special services $(.11, p=.005)$ to Risky Behavior $\left(R^{2}=.20\right)$. Thus, boys, students from lower income families, and students who received some special services in 6th grade had more Student-Teacher Conflict with teachers and engaged in more Risky Behavior in 6th grade.

Parameter estimates between latent variables (i.e., Difficult Temperament, StudentTeacher Conflict, and Risky Behavior) revealed significant paths from Difficult Temperament to Risky Behavior (.10, $p=.022)$ and from Difficult Temperament to Student-Teacher Conflict $(.25, p<.001)$, as well as from Student-Teacher Conflict to Risky Behavior (.32, $p<.001)$. These findings indicate that a student's more difficult temperament, measured at age $4 \frac{1}{2}$ years, was related to his or her risky behavior in 6th grade both directly and indirectly, through conflict with teachers. Specifically, early adolescents rated as having a more difficult temperament also had more student-teacher conflict, and more studentteacher conflict was related to an increased likelihood of engaging in more risky behavior.

\section{Tests for mediation}

Statistically significant path coefficients emerged from student gender and family income-to-needs ratio to Student-Teacher Conflict and Risky Behavior, from Difficult Temperament to Student-Teacher Conflict and Risky Behavior, and from Student-Teacher Conflict to Risky Behavior. Thus, confidence intervals of the products of indirect effects were calculated to test for the mediating role of Student-Teacher Conflict on associations between background characteristics (i.e., student gender and family income-to-needs ratio) and Risky Behavior, and between Difficult Temperament and Risky Behavior. Lower and upper 95\% confidence limits for the mediating role of Student-Teacher Conflict on the relation between student gender and Risky Behavior (lower $=.15$, upper $=.41$ ) and 


\begin{tabular}{lllllllllll}
\hline 6 & 7 & 8 & 9 & 10 & 11 & 12 & 13 & 14 & 15 & 16 \\
\hline
\end{tabular}

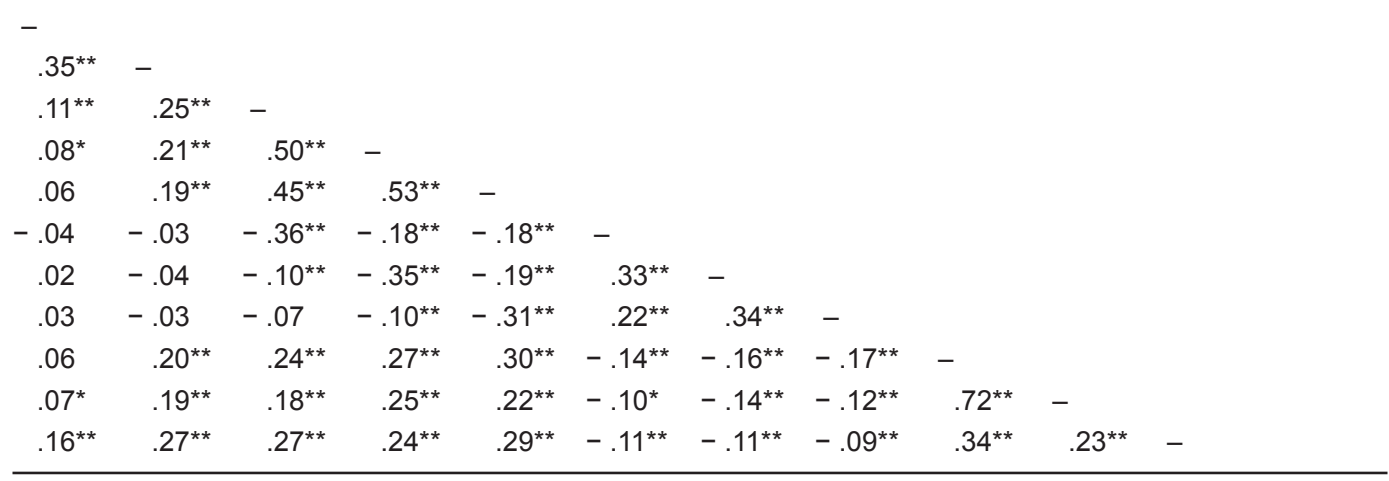

family income-to-needs ratio and Risky Behavior (lower $=.02$, upper $=.06$ ), did not include zero, indicating Student-Teacher Conflict mediated these relationships. In addition, a 95\% confidence interval for the mediating role of Student-Teacher Conflict on the association between Difficult Temperament and Risky Behavior (upper $=.46$, lower $=.17$ ) did not include zero, indicating Student-Teacher Conflict also mediated this association. Thus, a mechanism by which students' background and difficult temperament characteristics are associated with risky behavior in early adolescence is the existence of conflict with teachers.

\section{Model 2: Student-teacher closeness and risky behavior}

Figure 2 shows standardized parameter estimates for this model. Regression weights for all of the observed variables loading on latent variables were statistically significant, providing support for the latent variables in this model. The model provided good fit: $\chi_{56}^{2}=237(p<.001)$, IFI $=.92$, TLI $=.86$, CFI $=.92$, RMSEA $=.05$ (Byrne, 2001). Squared multiple correlations indicate that the model explained $15 \%$ of variance in StudentTeacher Closeness and 16\% of variance in Risky Behavior. In terms of background characteristics, examination of path coefficients in this model pointed to significant paths from student gender $(.36, p<.001)$ and family income-to-needs ratio $(.16, p<.001)$ to StudentTeacher Closeness, and from family income-to-needs ratio $(-.09, p=.009)$ and special services $(.13, p=.002)$ to Risky Behavior. That is, girls and children from higher income families had more Student-Teacher Closeness with teachers. Children from lower income families and children who received some special services in 6th grade engaged in more Risky Behavior in 6th grade. 
Path coefficients between latent variables (i.e., Difficult Temperament, StudentTeacher Closeness, and Risky Behavior) revealed significant paths from Difficult Temperament to Risky Behavior $(.18, p<.001)$ and from Student-Teacher Closeness to Risky Behavior $(-.24, p<.001)$. These findings suggest an early adolescent's more difficult temperament, measured at age $4 \frac{1}{2} 2$ years, directly contributed to his or her risky behavior in 6th grade. In addition, early adolescents with closer relationships with teachers also engaged in less risky behavior in 6th grade.

\section{Test for mediation}

Because of the statistically significant paths from family income to Student-Teacher Closeness and Risky Behavior and from Student-Teacher Closeness to Risky Behavior, a confidence interval of the product of indirect effect was calculated to test for the mediating role of Student-Teacher Closeness on the association between family income-toneeds ratio and Risky Behavior. Lower and upper 95\% confidence limits (lower $=.03$, upper $=.07$ ) did not include zero, indicating Student-Teacher Closeness mediated this relationship. This finding suggests that a mechanism by which students' lower family income is related with more risky behavior in early adolescence is the lack of positive connections with significant adults (i.e., teachers) in their lives.

\section{Discussion}

Three main findings emerged from this study. First, and congruent with previous research, we found evidence that students' background characteristics (i.e., gender, family income, and special services) and difficult temperament (assessed at age $4^{1 / 2}$ years by maternal report) influenced risky behavior in 6th grade. Students from lower income families, boys, students receiving special services, and those with more difficult temperaments were more likely to engage in risky behavior in 6th grade. Second, background characteristics and difficult temperaments also affected student-teacher relationship quality, such that students from lower income families, boys, students receiving special services, and students with more difficult temperaments were more likely to have conflictual relationships with teachers in 4th, 5th, and 6th grades, and students from higher income families and receiving no special services were more likely to have close relationships with teachers in 4th, 5th, and 6th grades. Finally, we found student-teacher conflict mediated the associations between background characteristics (gender, family income, and special services) and risky behavior, as well as difficult temperament and risky behavior. In addition, student-teacher closeness mediated the association between student family income and risky behavior. This study provides preliminary evidence that early adolescents' relationships with significant adults (i.e., teachers) may be mechanisms explaining why some individuals are more likely than others to engage in negative behaviors such as maladaptive risk-taking. Together, these findings point to the importance of proximal processes between individuals and their environment in understanding developmental outcomes in early adolescence (Bronfenbrenner, 1999; Bronfenbrenner and Morris, 1998). Each of these findings will be discussed in turn.

Our results add to previous research indicating that certain student background characteristics influence student-teacher relationship quality and risky behavior. Our find- 
ing that students from lower income families were likely to have more conflict and less closeness with teachers in grades 4 to 6 is consistent with studies of younger students (O'Connor and McCartney, 2006; Pianta et al., 2005; Rydell et al., 2005), and our finding that lower income students were more likely to engage in risky behavior is similar to other work (Blum et al., 2001; Edwards et al., 2007; Harris et al., 2002). Consistent with previous research, we found male students had more conflict in relationships with teachers than female students, and female students had closer relationships with teachers than male students. Indeed, there is a robust literature supporting the role of gender in student-teacher relationship quality, with findings consistently pointing to an increased likelihood of more conflict in relationships for boys, and more closeness in relationships for girls (Baker, 2006; Hamre and Pianta, 2001; Howes et al., 2000; Saft and Pianta, 2001). In addition, these findings are congruent with other work showing that males and students who receive special services are more likely to engage in risky behavior (Blum et al., 2001; Zuckerman, 2007).

Consistent with previous research (e.g., Bijttebier et al., 2003; Wills et al., 2000), we found difficult temperament assessed at age $4 \frac{1}{2} 2$ years predicted early adolescents' level of engagement in risky behavior, while also considering other well-known predictors of risky behavior (i.e., gender, family income, and special services). These findings speak to the potentially predictive value of temperament, given the longitudinal nature of our findings across a seven-year period. Students' temperament ratings at age $4 \frac{1}{2} 2$ years predicted outcomes (student-teacher relationship quality) and behaviors (risk-taking) as late as 6th grade, and these findings are congruent with other research showing the relationship between early temperament and later outcomes (Caspi and Silva, 1995; Kagan et al., 1988; Resnick et al., 1986; Rothbart and Posner, 2005). In addition, the link between children's difficult temperament and risky behavior points to the value of identifying and establishing protective mechanisms for children with difficult temperaments to deter their engagement in risky behaviors in adolescence. Indeed, assessments of temperament may be used as "early warning systems" that aid parents and teachers in identifying and preventing problems that may emerge as children move through school and transition into adolescence.

We also found difficult temperament contributed to student-teacher relationship quality in 4th, 5th, and 6th grades. Our results showed that a more difficult temperament was related to greater student-teacher conflict. Although there is little research examining associations between children's temperament and the quality of their relationships with teachers, our finding regarding student-teacher conflict is consistent with studies showing that children's antisocial and aggressive behavior is related to poor student-teacher relationship quality (Eisenhower et al., 2007; Hamre and Pianta, 2001; Ladd et al., 1999; Voisin et al., 2006). There is also evidence that uninhibited children and children low in effortful control are likely to have conflict with their teachers (Rudasill \& Rimm-Kaufman, 2009).

Finally, we found student-teacher conflict mediated the relation between background characteristics (i.e., family income and gender) and risky behavior, and difficult temperament and risky behavior. That is, coming from a low income family, being male, and having a more difficult temperament were associated with greater student-teacher conflict, and greater student-teacher conflict was associated with more risky behavior. This finding points to student-teacher relationship quality as a mechanism by which students with 
certain background characteristics or difficult temperaments may be at increased risk for engaging in risky behavior. This finding ties together two bodies of literature; one suggests positive student-teacher relationships may buffer students from engaging in maladaptive behavior (e.g., Wentzel, 2002), and the other indicates that student-teacher relationship quality is predicated, in part, by student characteristics, such as temperament (e.g., Rudasill \& Rimm-Kaufman, 2009). In addition, we found that closeness mediated the relation between family income and risky behavior. Although we did not find support for a mediating role for student-teacher closeness in the relation between difficult temperament and risky behavior, our finding that greater levels of student-teacher closeness were related to less risky behavior support the idea that positive student-teacher relationships may buffer early adolescents from engaging in risky behavior. Both of these conclusions are consistent with our theoretical underpinnings as well as previous research, all of which point to the role of connectedness and belonging to others as important protective mechanisms for students' positive outcomes. It could be that students who feel connected to significant others (e.g., teachers) have a sense of belonging that protects them from reaching out to other sources of comfort (e.g., peer approval) that may involve negative behavior and outcomes. Put another way, when students feel that school is a welcoming and comfortable place to be, they may be less likely to engage in risky behaviors as a means of escape (i.e., substance abuse) or to gain approval from others.

Results from this study highlight the need for understanding how early ratings of temperament, as well as background characteristics, relate to and work with elements of the environment (e.g., student-teacher relationship quality) to contribute to risk-taking behaviors in early adolescence. Consistent with bioecological theory (Bronfenbrenner \& Morris, 1998), our findings demonstrate that temperamental style contributes to the nature of student-teacher relationships, one type of proximal process that influences development. In our study, students with more difficult temperaments were more likely to have more conflict with teachers, and this finding may be understood in the context of proximal processes. Students with more difficult temperaments demand more attention (i.e., proximal processes) from their teachers, and this attention, in turn, may manifest as conflict in the student-teacher relationship. Similarly, proximal processes such as those between students and teachers may work to buffer or exacerbate an individual's likelihood of engaging in maladaptive risky behavior.

Our research supports bioecological theory in that it offers a context for understanding how proximal processes can impinge upon risky behavior. First, these findings support the value of relatedness with teachers as a protective mechanism against risky behaviors. Second, this study demonstrates the richness of bioecological theory for examining the proximal contexts that are predictive of risky behavior. The bioecological perspective thus presents a useful framework for systematically addressing the issues associated with maladaptive risk-taking. However, it is important to note that only microsystem-level variables were examined in this study.

\section{Limitations}

Several limitations to the present study require mention. First, our sample was relatively homogenous in terms of race/ethnicity. Indeed, most adolescents in the sample 
were White. In addition, there was little variation in the quality of student-teacher relationships and risky behavior. That is, students in this sample had relatively low levels of conflict and high levels of closeness with teachers and engaged in relatively little risky behavior. There was also limited variability in the number of hours per week students received special services (such as special education or English as a second language resource), with the majority of students in the sample receiving no special services. In addition, the reliability estimates for the temperament subscales were a bit low but nonetheless consistent with other studies using the CBQ and other measures of temperament (Kochanska et al., 1994; Putnam and Rothbart, 2006; Rothbart et al., 2001). Studentteacher relationship quality scores were based solely on teacher report; assessment of student-teacher relationships would be strengthened with observational measures.

Because this was not an experimental study, we cannot draw inferences of true cause and effect relations between the research variables, yet the findings are consistent with previous research. We argue, though, that the use of temperament ratings from age $4 \frac{1}{2}$ years (setting a temporal precedent) and controlling for other theoretically-relevant influences (i.e., background variables) presents preliminary evidence of a causal link between temperament, student-teacher relationship quality, and risky behavior in early adolescence. Finally, although there was a good fit between the data and hypothesized models, the models need to be validated with other groups in alternative contexts to continue building evidence supporting them.

\section{Implications for practice and future research}

This study's results have implications for practice and future research. In terms of practice, this study joins a wealth of research informing teachers, school administrators, and teacher trainers about the value of positive student-teacher relationships for students in early adolescence. Positive behavioral support systems (i.e., those that emphasize preventive, rather than reactive, responses to student behavior problems) highlight the teacher's role in creating a school and classroom climate where positive student-teacher interactions far outnumber negative interactions (Sugai \& Horner, 2002). From these perspectives, teacher training and professional development could focus broadly on the contributions of school-wide positive behavior support (Sugai \& Horner, 2002, 2006), and more specifically on the benefits of avoiding student-teacher conflict, for decreasing negative student behavior and enhancing student outcomes. A similar emerging model in special education research situates student success within an ecological context. This model, Response to Intervention (RTI), directs attention to the fit between student and classroom environment for understanding student outcomes (Murawski \& Hughes, 2009). From this perspective, professional development workshops could be offered to alert teachers to the prevalence of maladaptive risk-taking, even among early adolescents, and how they might lessen its likelihood through fostering better relationships with their students. Congruent with the bioecological model, results reported here support educational practices that consider the importance of the "whole child" (i.e., emphasis on both academic and socioemotional processes) to promote long-term healthy development.

The quality of students' relationships with their teachers appears to have important implications for their engagement in risky behavior. Further research is needed to iden- 
tify the relational nuances that help or hinder relationship-building between students and teachers. Longitudinal research designs could be employed to examine the contributions of student-teacher relations to both adaptive and maladaptive risk-taking over time and how these variables influence school-related outcomes like school completion. Experimental research could test whether interventions that promote stronger student-teacher relations actually cause early adolescents to engage less frequently in maladaptive risktaking behavior. The models investigated in this study should be tested also with different student populations (e.g., greater representation of non-White ethnic groups and students diagnosed with attention deficit hyperactivity disorder) in varying contexts (e.g., Western versus non-Western countries, urban versus rural schools, and middle versus high schools) to more firmly establish the extent of their validity. Further, future research should identify effective approaches for helping teachers develop closer relationships with students, particularly those with difficult temperaments, and those from lower income families, boys, and those receiving special school services. In addition, future research should examine the contributions of student-teacher relationships to other outcomes (e.g., academic achievement and enrollment in postsecondary education) through middle and late adolescence and early adulthood. Future research should incorporate data from other sources to assess temperament, student-teacher relationship quality, and risky behavior. For example, student-teacher relationship quality could be measured from student report, and risky behavior could be measured using discipline referrals and juvenile justice data. Certainly, further investigations would be strengthened with additional data sources.

This study extends the current literature on the contribution of temperament to students' relationships with teachers and their risky behavior. Furthermore, this study bridges the temperament, student-teacher relationship, and risky behavior literatures by illustrating the mediating role of student-teacher relationship quality on the associations between student background characteristics and maladaptive risky behavior and between difficult temperament and maladaptive risky behavior. As such, findings from this study lend support to practices in schools that are intended to foster positive relationships between students and teachers, particularly in early adolescence.

Acknowledgments - This study was conducted by the NICHD Early Child Care Research Network supported by NICHD through a cooperative agreement that calls for scientific collaboration between the grantees and the NICHD staff.

\section{References}

Arbuckle, 2007 - J. L. Arbuckle, AMOS 6. 0 update to the AMOS user's guide, Smallwaters Corporation, Chicago (2007).

Babalola, 2004 - S. Babalola, Perceived peer behavior and the timing of sexual debut in Rwanda: A survival analysis of youth data, Journal of Youth and Adolescence 33 (2004), pp. 353-363.

Baker, $2006 \cdot$ J. A. Baker, Contributions of teacher-child relationships to positive school adjustment during elementary school, Journal of School Psychology 44 (2006), pp. 211-229.

Beitchman et al., 2001 - J. H. Beitchman, B. Wilson, L. Douglas, A. Young, and E. Adlaf, Substance use disorders in young adults with and without LD: Predictive and concurrent relationships, Journal of Learning Disabilities 34 (2001), pp. 317-322. 
Bijttebier et al., 2003 • P. Bijttebier, H. Vertommen, and K. Florentie, Risk-taking behavior as a mediator of the relationship between children's temperament and injury liability, Psychology $\mathcal{E}$ Health 18 (2003), pp. 645-653.

Birch and Ladd, 1997 - S. H. Birch and G. W. Ladd, The teacher-child relationship and children's early school adjustment, Journal of School Psychology 35 (1997), pp. 61-79.

Blum et al., 2001 - R. W. Blum, A. Kelly, and M. Ireland, Health-risk behaviors and protective factors among adolescents with mobility impairments and learning and emotional disabilities, Journal of Adolescent Health 28 (2001), pp. 481-490.

Bronfenbrenner, 1995 - U. Bronfenbrenner, The bioecological model from a life course perspective: Reflections of a participant observer. In: P. Moen, G. H. Elder Jr., and K. Luscher, editors, Examining lives in context: Perspectives on the ecology of human development. American Psychological Association, Washington, DC (1995), pp. 619-647.

Bronfenbrenner, 1999 - U. Bronfenbrenner, Environments in developmental perspective: Theoretical and operational models. In: S. L. Friedman and T. D. Wachs, editors, Measuring environment across the lifespan: Emerging methods and concepts, American Psychological Association, Washington, DC (1999), pp. 3-28.

Bronfenbrenner and Morris, 1998 - U. Bronfenbrenner and P. A. Morris In: R. M. Lerner, editor, The ecology of developmental processes (5th ed), Theoretical models of human development Vol. 1, Wiley, New York (1998), pp. 993-1028.

Byrne, 2001 • B. M. Byrne, Structural equation modeling with AMOS, Erlbaum, Mahwah, NJ (2001).

Byrnes et al., 1999 - J. P. Byrnes, D. C. Miller, and W. D. Schafer, Gender differences in risk taking: A meta-analysis, Psychological Bulletin 125 (1999), pp. 367-383.

Caspi et al., 1997 - A. Caspi, H. Harrington, T. E. Moffitt, D. Begg, N. Dickson, and J. Langley et al., Personality differences predict health-risk behaviors in young adulthood: Evidence from a longitudinal study, Journal of Personality E Social Psychology 73 (1997), pp. 1052-1063.

Caspi and Silva, 1995 - A. Caspi and P. A. Silva, Temperamental qualities at age three predict personality traits in young adulthood: Longitudinal evidence from a birth cohort, Child Development 66 (1995), pp. 486-498.

Chassin et al., 2004 • L. Chassin, A. Hussong, M. Barrera Jr., B. Molina, R. Trim, and J. Ritter, Adolescent substance use. In: R. Lerner and L. Steinberg, editors, Handbook of adolescent psychology (2nd ed.), Wiley, New York (2004), pp. 665-696.

Cohen et al., 2003 - J. Cohen, P. Cohen, S. G. West, and L. S. Aiken, Applied multiple regression/correlation analysis for the behavioral sciences (3rd ed.), Erlbaum, Mahwah, NJ (2003).

Conger et al., 1997 - R. D. Conger, K. J. Conger, and G. H. Elder, Family economic hardship and adolescent academic performance: Mediating and moderating processes. In: G. J. Duncan and J. BrooksGunn, editors, Consequences of growing up poor, Sage, New York (1997), pp. 288-310.

Conger and Elder, $1994 \cdot$ R. Conger and G. H. Elder, Families in troubled times: Adapting to change in rural America, A. de Gruyter, New York (1994).

DiLalla et al., 2004 • L. F. DiLalla, J. L. Marcus, and M. V. Wright-Phillips, Longitudinal effects of preschool behavioral styles on early adolescent school performance, Journal of School Psychology 42 (2004), pp. 385-401.

Dowdell, 2002 • E. B. Dowdell, Urban seventh graders and smoking: A health risk behavior assessment, Issues in Comprehensive Pediatric Nursing 25 (2002), pp. 217-229.

Edwards et al., 2007 • O. W. Edwards, V. E. Mumford, M. A. Shillingford, and R. Serra-Roldan, Developmental assets: A prevention framework for students considered at risk, Children E Schools 29 (2007), pp. 145-153.

Eisenberg et al., 2008 - N. Eisenberg, C. Hofer, T. L. Spinrad, E. T. Gershoff, C. Valiente, and S. Losoya et al., Understanding mother-adolescent conflict discussions: Concurrent and across-time prediction from youths' dispositions and parenting, Monographs of the Society for Research in Child Development 73 (2008) 2, Serial No. 290.

Eisenhower et al., 2007 - A. S. Eisenhower, B. L. Baker, and J. Blacher, Early student-teacher relationships of children with and without intellectual disability: Contributions of behavioral, social, and selfregulatory competence, Journal of School Psychology 45 (2007), pp. 363-383.

Evans, 1996 - M. A. Evans, Reticent primary grade children and their more talkative peers: Verbal, nonverbal, and self-concept characteristics, Journal of Educational Psychology 88 (1996), pp. 739-749.

Feldstein and Miller, 2006 - S. W. Feldstein and W. R. Miller, Substance use and risk-taking among adolescents, Journal of Mental Health 15 (2006), pp. 633-643. 
Gardner and Steinberg, 2005 - M. Gardner and L. Steinberg, Peer influence on risk taking, risk preference, and risky decision making in adolescence and adulthood: An experimental study, Developmental Psychology 41 (2005), pp. 625-635.

Gregory and Weinstein, 2004 - A. Gregory and R. S. Weinstein, Connection and regulation at home and in school: Predicting growth in achievement for adolescents, Journal of Adolescent Research 19 (2004), pp. 405-427.

Hamre and Pianta, 2001 • B. K. Hamre and R. C. Pianta, Early teacher-child relationships and the trajectory of children's school outcomes through eighth grade, Child Development 72 (2001), pp. 625-638.

Harris et al., 2002 - K. M. Harris, G. J. Duncan, and J. Boisjoly, Evaluating the role of 'nothing to lose' attitudes on risky behavior in adolescence, Social Forces 80 (2002), pp. 1005-1039.

Herrero et al., 2006 • J. Herrero, E. Estevez, and G. Musitu, The relationships of adolescent school-related deviant behaviour and victimization with psychological distress: Testing a general model of the mediational role of parents and teachers across groups of gender and age, Journal of Adolescence 29 (2006), pp. 671-690.

Howes et al., 2000 - C. Howes, L. C. Phillipsen, and E. Peisner-Feinberg, The consistency of perceived teacher-child relationships between preschool and kindergarten, Journal of School Psychology 38 (2000), pp. 113-132.

Hu and Bentler, $1999 \bullet$ L. T. Hu and P. Bentler, Cutoff criteria for fit indices in covariance structure analysis: Conventional criteria versus new alternatives, Structural Equation Modeling 6 (1999), pp. 1-55.

Hughes et al., 2005 - J. N. Hughes, K. A. Gleason, and D. Zhang, Relationship influences on teachers' perceptions of academic competence in academically at-risk minority and majority first grade students, Journal of School Psychology 43 (2005), pp. 303-320.

Justice et al., 2008 - L. M. Justice, E. A. Cottone, A. Mashburn, and S. E. Rimm-Kaufman, Relationships between teachers and preschoolers who are at risk: Contribution of children's language skills, temperamentally based attributes, and gender, Early Education and Development 19 (2008), pp. 600-621.

Kagan, 1998 - J. Kagan In: N. Eisenberg, editor, Biology and the child (5 ed), Social, emotional, and personality development Vol. 3, Wiley, New York (1998), pp. 177-236.

Kagan et al., 1988 - J. Kagan, S. Resnick, and N. Snidman, Biological bases of childhood shyness, Science 240 (1988), pp. 167-171.

Kochanska et al., 1994 • G. Kochanska, K. DeVet, M. Goldman, K. Murray, and S. P. Putnam, Maternal reports of conscience development and temperament in young children, Child Development 65 (1994), pp. 852-868.

Kuperman et al., 2001 • S. Kuperman, S. S. Schlosser, J. R. Kramer, K. Bucholz, V. Hesselbrock, and T. Reich et al., Developmental sequence from disruptive behavior diagnosis to adolescent alcohol dependence, American Journal of Psychiatry 158 (2001), pp. 2022-2026.

Ladd et al., 1999 - G. W. Ladd, S. H. Birch, and E. S. Buhs, Children's social and scholastic lives in kindergarten: Related spheres of influence?, Child Development 70 (1999), pp. 1373-1400.

Lynch and Cicchetti, 1997 - M. Lynch and D. Cicchetti, Children's relationships with adults and peers: An examination of elementary and junior high school students, Journal of School Psychology 35 (1997), pp. 81-99.

MacKinnon et al., 2007 • D. P. MacKinnon, M. S. Fritz, J. Williams, and C. M. Lockwood, Distribution of the product confidence limits for the indirect effect: Program PRODCLIN, Behavior Research Methods 39 (2007), pp. 384-389.

Marsh et al., 2004 • H. W. Marsh, K. Hau, and Z. Wen, In search of golden rules: Comment on hypothesis-testing approaches to setting cutoff values for fit indexes and dangers in overgeneralizing Hut and Bentler's (1999) findings, Structural Equation Modeling 11 (2004), pp. 320-341.

Meehan et al., 2003 - B. T. Meehan, J. N. Hughes, and T. A. Cavell, Teacher-student relationships as compensatory resources for aggressive children, Child Development 74 (2003), pp. 1145-1157.

Moore et al., 2005 - D. J. Moore, J. H. Atkinson, H. Akiskal, R. Gonzalez, T. Wolfson, and I. Grant, Temperament and risky behaviors: A pathway to HIV?, Journal of Affective Disorders 85 (2005), pp. 191-200.

Murawski and Hughes, 2009 • W. W. Murawski and C. E. Hughes, Response to intervention, collaboration, and co-teaching: A logical combination for successful systemic change, Preventing School Failure 53 (2009), pp. 267-277.

Murray and Greenberg, 2001 - C. Murray and M. T. Greenberg, Relationships with teachers and bonds with school: Social emotional adjustment correlates for children with and without disabilities, Psychology in the Schools 38 (2001), pp. 25-41. 
Murray and Greenberg, 2006 - C. Murray and M. T. Greenberg, Examining the importance of social relationships and social contexts in the lives of children with high-incidence disabilities, The Journal of Special Education 39 (2006), pp. 220-233.

Mylant et al., 2002 - M. Mylant, B. Ide, E. Cuevas, and M. Meehan, Adolescent children of alcoholics: Vulnerable or resilient?, Journal of the American Psychiatric Nurses Association 8 (2) (2002), pp. 57-64.

NICHD Early Child Care Research Network, 2001 - NICHD Early Child Care Research Network, Nonmaternal care and family factors in early development: An overview of the NICHD Study of Early Child Care, Journal of Applied Developmental Psychology 22 (2001), pp. 559-579.

O'Connor and McCartney, 2006 • E. O'Connor and K. McCartney, Testing associations between young children's relationships with mothers and teachers, Journal of Educational Psychology 98 (2006), pp. 87-98.

Olsson et al., 2008 - A. Olsson, I. Fahlen, and S. Janson, Health behaviours, risk-taking and conceptual changes among schoolchildren aged 7 to 19 years in semi-rural Sweden, Child: Care, Health $\mathcal{E}$ Development 34 (2008), pp. 302-309.

Pianta, 2001 - R. C. Pianta, STRS Student Teacher Relationship Scale, Psychological Assessment Resources, Odessa, FL (2001).

Pianta et al., 2005 • R. C. Pianta, C. Howes, M. Burchinal, D. Bryant, R. Clifford, and D. Early et al., Features of pre-kindergarten programs, classrooms, and teachers: Do they predict observed classroom quality and child-teacher interactions?, Applied Developmental Psychology 9 (2005), pp. 144-159.

Pianta et al., 1995 - R. C. Pianta, M. S. Steinberg, and K. B. Rollins, The first two years of school: Teacherchild relationships and deflections in children's classroom adjustment, Development and Psychopathology 7 (1995), pp. 295-312.

Pilgrim et al., 1999 • C. Pilgrim, Q. Luo, K. A. Urberg, and X. Fang, Influence of peers, parents, and individual characteristics on adolescent drug use in two cultures, Merrill-Palmer Quarterly 45 (1999), pp. 85-107.

Pluess and Belsky, 2009 - M. Pluess and J. Belsky, Differential susceptibility to rearing experience: The case of childcare, The Journal of Child Psychology and Psychiatry 50 (2009), pp. 396-404.

Putnam and Rothbart, 2006 - S. P. Putnam and M. K. Rothbart, Development of short and very short forms of the Children's Behavior Questionnaire, Journal of Personality Assessment 87 (2006), pp. 102-112.

Reid et al., 2009 • G. J. Reid, R. Y. Hong, and T. J. Wade, The relation between common sleep problems and emotional and behavioral problems among 2- and 3-year olds in the context of known risk factors for psychopathology, Journal of Sleep Research 18 (2009), pp. 49-59.

Reio, 2010 • T. G. Reio Jr., What about adolescent curiosity and risk taking?. In: J. L. DeVitis and L. IrwinDeVitis, editors, Adolescent education: A reader, Peter Lang Publishing, New York (2010), pp. 99-109.

Reio et al., 2009 • T. G. Reio Jr., R. F. Marcus, and J. Sanders-Reio, The contribution of student and instructor relationships and attachment style to school completion, The Journal of Genetic Psychology 170 (2009), pp. 53-72.

Resnick et al., 1986 • S. M. Resnick, S. A. Berenbaum, I. I. Gottesman, and J. T. J. Bouchard, Early hormonal influences on cognitive functioning in congenital adrenal hyperplasia, Developmental Psychology 22 (1986), pp. 191-198.

Reyna and Farley, 2006 - V. F. Reyna and F. Farley, Risk and rationality in adolescent decision making: Implications for theory, practice, and public policy, Psychological Science in the Public Interest 7 (2006), pp. 1-44.

Roeser et al., 1996 • R. W. Roeser, C. Midgley, and T. C. Urdan, Perceptions of the school psychological environment and early adolescents' psychological and behavioral functioning in school: The mediating role of goals and belonging, Journal of Educational Psychology 88 (1996), pp. 408-422.

Rothbart et al., 1994 - M. K. Rothbart, S. A. Ahadi, and K. L. Hershey, Temperament and social behavior in childhood, Merrill-Palmer Quarterly 40 (1994), pp. 21-39.

Rothbart et al., 2001 - M. K. Rothbart, S. A. Ahadi, K. L. Hershey, and P. Fisher, Investigations of temperament at three to seven years: The Children's Behavior Questionnaire, Child Development 72 (2001), pp. 1394-1408.

Rothbart and Bates, 2006 - M. K. Rothbart and J. E. Bates In: N. Eisenberg, editor, Temperament (6th ed), Social, emotional, and personality development Vol. 3, Wiley, New York (2006), pp. 99-166.

Rothbart and Posner, 2005 - M. K. Rothbart and M. I. Posner, Genes and experience in the development of executive attention and effortful control, New Directions for Child \& Adolescent Development 109 (2005), pp. 101-108. 
Rudasill and Rimm-Kaufman, 2009 • K. M. Rudasill and S. E. Rimm-Kaufman, Teacher-child relationship quality: The roles of child temperament and teacher-child interactions, Early Childhood Research Quarterly 24 (2009), pp. 107-120.

Rudasill et al., 2006 • K. M. Rudasill, S. E. Rimm-Kaufman, L. M. Justice, and K. Pence, Temperament and language skills as predictors of teacher-child relationship quality in preschool, Early Education $\mathcal{E}$ Development 17 (2) (2006), pp. 271-291.

Rydell et al., 2005 - A. M. Rydell, G. Bohlin, and L. B. Thorell, Representations of attachment to parents and shyness as predictors of children's relationships with teachers and peer competence in preschool, Attachment \& Human Development 7 (2005), pp. 187-204.

Saft and Pianta, 2001 - E. W. Saft and R. C. Pianta, Teachers' perceptions of their relationships with students: Effects of child age, gender, and ethnicity of teachers and children, School Psychology Quarterly 16 (2001), pp. 125-141.

Stacy et al., 1990 - A. W. Stacy, B. R. Flay, S. Sussman, K. S. Brown, S. Santi, and J. A. Best, Validity of alternative self-report indices of smoking among adolescents, Psychological Assessment: A Journal of Consulting and Clinical Psychology 2 (1990), pp. 442-446.

Steinberg, 2003 - L. Steinberg, Risk-taking in adolescence: What changes and why?, Paper presented at the meeting of the New York Academy of Sciences on Adolescent Brain Development, New York, NY, September, 2003.

Steinberg, 2007 • L. Steinberg, Commentary, Monographs of the Society for Research in Child Development 72 (2) (2007), pp. 76-80.

Steinberg, 2008 - L. Steinberg, A social neuroscience perspective on adolescent risk-taking, Developmental Review 28 (2008), pp. 78-106.

Stuhlman and Pianta, 2002 - M. W. Stuhlman and R. C. Pianta, Teachers' narratives about their relationships with children: Associations with behavior in classrooms, School Psychology Review 31 (2002), p. 148.

Sugai and Horner, 2002 • G. Sugai and R. H. Horner, The evolution of discipline practices: School-wide positive behavior supports, Child and Family Behavior Therapy 24 (2002), pp. 23-50.

Sugai and Horner, 2006 - G. Sugai and R. H. Horner, A promising approach for expanding and sustaining school-wide positive behavior support, School Psychology Review 35 (2006), pp. 245-259.

Swearer and Espelage, 2004 - S. M. Swearer and D. L. Espelage, A social-ecological framework of bullying among youth. In: D. L. Espelage and S. M. Swearer, editors, Bullying in American schools: A socialecological perspective on prevention and intervention, Erlbaum, Mahwah, NJ (2004), pp. 1-12.

Thomas and Chess, 1977 - A. Thomas and S. Chess, Temperament and development, Brunner/Mazel, Oxford, England (1977).

Thompson et al., 2010 - R. Thompson, J. K. Tabone, A. J. Litrownik, E. C. Briggs, J. M. Hussey, and D. J. English et al., Early adolescent risk behavior outcomes of childhood externalizing behavioral trajectories, The Journal of Early Adolescence (2010), advance online publication; doi: 10. $1177 / 0272431609361203$.

Voisin et al., 2006 • D. R. Voisin, R. J. DiClemente, L. F. Salazar, R. A. Crosby, and L. W. Yarber, Ecological factors associated with STD risk behaviors among detained female adolescents, Social Work 51 (2006), pp. 71-79.

Wentzel, 1998 - K. R. Wentzel, Social relationships and motivation in middle school: The role of parents, teachers, and peers, Journal of Educational Psychology 90 (1998), pp. 202-209.

Wentzel, 2002 - K. R. Wentzel, Are effective teachers like good parents? Teaching styles and student adjustment in early adolescence, Child Development 73 (2002), pp. 287-301.

Williams et al., 2000 - G. C. Williams, V. A. Hedberg, E. M. Cox, and E. L. Deci, Extrinsic life goals and health-risk behaviors in adolescents, Journal of Applied Social Psychology 30 (2000), pp. 1756-1771.

Wills et al., 2000 - T. A. Wills, J. M. Sandy, and A. Yaeger, Temperament and early onset of substance abuse: An epigenetic approach to risk and protection, Journal of Personality 68 (2000), pp. 1127-1152.

Wyrick and Rudasill, 2009 - A. J. Wyrick and K. M. Rudasill, Parent involvement as a predictor of teacher-child relationship quality in third grade, Early Education and Development 20 (2009), pp. 1-20.

Zimmer-Gembeck et al., 2006 • M. J. Zimmer-Gembeck, H. M. Chipuer, M. Hanisch, P. A. Creed, and L. McGregor, Relationships at school and stage-environment fit as resources for adolescent engagement and achievement, Journal of Adolescence 29 (2006), pp. 911-933.

Zuckerman, 2007 - M. Zuckerman, Sensation seeking and risky behavior, American Psychological Association, Washington, DC (2007). 